Wilfrid Laurier University

Scholars Commons @ Laurier

Lyle S. Hallman Social Work Faculty

Publications

Lyle S. Hallman Faculty of Social Work

Winter 2008

\title{
Research Priorities in Pediatric Palliative Care: A Delphi Study
}

\author{
Rose Steele \\ York University \\ Harvey Bosma \\ University of British Columbia \\ Meghan Fletcher Johnston \\ University of British Columbia \\ Susan Cadell \\ Wilfrid Laurier University, scadell@wlu.ca \\ Betty Davies \\ University of California -- San Francisco
}

See next page for additional authors

Follow this and additional works at: https://scholars.wlu.ca/scwk_faculty

\section{Recommended Citation}

Steele, Rose; Bosma, Harvey; Fletcher Johnston, Meghan; Cadell, Susan; Davies, Betty; Siden, Hal; and Straatman, Lynn, "Research Priorities in Pediatric Palliative Care: A Delphi Study" (2008). Lyle S. Hallman Social Work Faculty Publications. 12.

https://scholars.wlu.ca/scwk_faculty/12

This Article is brought to you for free and open access by the Lyle S. Hallman Faculty of Social Work at Scholars Commons@ @aurier. It has been accepted for inclusion in Lyle S. Hallman Social Work Faculty Publications by an authorized administrator of Scholars Commons @ Laurier. For more information, please contact scholarscommons@wlu.ca. 


\section{Authors}

Rose Steele, Harvey Bosma, Meghan Fletcher Johnston, Susan Cadell, Betty Davies, Hal Siden, and Lynn Straatman 


\section{Research Priorities in Pediatric Palliative Care: a Delphi Study}

ROSE STEELE, School of Nursing, Faculty of Health, York University, Toronto, Ontario, HARVEY BOSMA, School of Social Work, University of British Columbia, Vancouver, British Columbia, MEAGHEN FLETCHER JOHNSTON, School of Social Work, University of British Columbia, Vancouver, British Columbia, SUSAN CADELL, Faculty of Social Work, Wilfrid Laurier University, Waterloo, Ontario, Canada, BETTY DAVIES, Department of Family Health Care Nursing, University of California, San Francisco, California, USA, HAL SIDEN, Department of Pediatrics, University of British Columbia, Vancouver, British Columbia, LYNN STRAATMAN, Faculty of Medicine, University of British Columbia, Vancouver, British Columbia, Canada

\begin{abstract}
Background: Pediatric palliative care is increasingly recognized to be a specialized type of care requiring specific skills and knowledge, yet, as found in several countries, there is little available research evidence on which to base care. Objectives: The goal of the project was to achieve consensus among palliative care practitioners and researchers regarding the identification of pertinent lines of research. Method: A Delphi technique was used with an interdisciplinary panel $(n=14-16)$ of researchers and frontline clinicians in pediatric palliative care in Canada. Results: Four priority research questions were identified: What matters most for patients and parents receiving pediatric palliative services? What are the bereavement needs of families in pediatric palliative care? What are the best practice standards in pain and symptom management? What are effective strategies to alleviate suffering at the end of life? Conclusions: These identified priorities will provide guidance and direction for research efforts in Canada, and may prove useful in providing optimal care to patients and families in pediatric palliative care.
\end{abstract}

Résumé / Contexte: De plus en plus les soins palliatifs pédiatriques sont reconnus comme étant une approche de soins specialisés nécessitant des connaissances et des habiletés particulières. Cependant, comme nous l'avons constaté dans plusieurs pays, il existe peu de résultats de recherche sur lesquels on peut s'appuyer pour juger du bien-fondé de ces soins. Objectif: Le but de ce projet était de pouvoir atteindre un concensus chez les professionels de la santé et les chercheurs en soins palliatifs afin de déterminer et d'identifier des objectifs de recherche. Méthode: Nous avons utilisé la méthode Delphi et avons ainsi recruté un panel interdisciplinaire $(n=14-16)$ composé de chercheurs et de cliniciens de première ligne engagés en soins palliatifs au Canada. Résultats: Les quatres questions identifiées comme étant prioritaires pour la recherche en ce domaine sont les suivantes: Quelles sont les choses les plus importantes pour les patients et leurs parents qui ont recours aux soins palliatifs? Quels sont les services de soutien dont les familles endeuillées ont besoin? Quelles sont les meilleurs pratiques cliniques pour contrôler la douleur et les symptômes? Quelles sont les meilleures stratégies pour alléger la souffrance en fin de vie? Les priorités ainsi identifiées pourront servir de lignes de conduite pour diriger la recherche en ce domaine au Canada et pourront sûrement aider à dispenser des soins palliatifs optimaux aux patients et leur famille.

\section{INTRODUCTION}

The World Health Organization defines palliative care as an approach to care that improves the quality of life of patients and their families facing life-threatening illness (1). Pediatric palliative and end-of-life care, an emerging area in the health field, is increasingly recognized as a specialized type of care requiring specific skills and knowledge (2). Within this burgeoning field, health care providers face diverse challenges associated with disease trajectories that are manifested in unpredictable ways (3), lengthy and often complex illness conditions (4), and advances in new technologies, treatments, and drugs.

While no statistics are available on the current use of pediatric palliative services, in Canada approximately 3,500 children die each year (5). Many of the siblings and parents of these children may require bereavement care services. After eliminating accidental deaths, suicides, and murders, it might be appropriate for two-thirds of those children to receive pediatric palliative care. In addition, there are many children with life-limiting conditions who could benefit from the symptom management, sibling and family support, and respite care associated with pediatric palliative care. Sources estimate that one in 1,000 children in the U.K. would appropriately benefit from a pediatric palliative approach $(4,6)$. A similar situation is expected in Canada. Yet, given this potential need, there is little research evidence on which to base care (7).

\section{PEDIATRIC PALLIATIVE NEW EMERGING TEAM}

Having recognized the growing need for research in palliative care, the Canadian Institutes 
of Health Research and partners launched a palliative and end-of-life care initiative that reflected the multiple needs of the palliative care research community. The initiative was designed to support infrastructure development, enhance interdisciplinary research collaboration, encourage the development of early career researchers, and attract trainees to this emerging area. One of the components of the initiative was a five-year New Emerging Team (NET) grant designed to build capacity and to promote the formation of new research teams or the growth of small existing teams. The NET proposal titled "Transitions in Pediatric Palliative and End-of-life Care" became the only pediatric team funded through this program. This pediatric team is known as the PEDPALNET.

The main goals of the PEDPALNET were established by the five core members $(\mathrm{SC}, \mathrm{BD}$, HS, RS, LS) and included:

- to undertake cross-sectional and longitudinal research;

- to establish and support new investigators;

- to create an innovative model of collaborative, multidisciplinary/multi-institutional work supported by best practices via electronic collaboration;

- to create resources for children, families, practitioners, health service providers, and policymakers; and

- to create an evidence base for improved policy and practice.

Team members were cognizant that given the lack of research in pediatric palliative care and the limited available resources for research, it was imperative that initial studies both laid the groundwork for an ongoing program of research and addressed the most urgent areas that require evidence. The first step in identifying which areas to address involved a literature review to determine if research priorities had been previously identified.

\section{LITERATURE REVIEW}

It has often been asserted, in recent years, that research development in pediatric palliative care is important. For example, the American Academy of Pediatrics (AAP) (8) released a statement in which it said continued development of pediatric palliative care through research and education is essential for improvement of services. Recommendations were to conduct clinical research concerning the effectiveness and benefits of pediatric palliative care interventions, especially pain and symptom management, grief and bereavement counselling, and models of service provision. The Institute of Medicine (IOM) (9) said that better data and scientific knowledge are needed to guide efforts to deliver more effective care, educate professionals to provide such care, and design supportive public policies. Specific research priorities included: the effectiveness of clinical interventions, including symptom management; methods for improving communication and decision making; innovative arrangements for delivering, coordinating, and evaluating care, including interdisciplinary care teams and quality improvement strategies; and different approaches to bereavement care.

While the number of published articles relevant to pediatric palliative care is increasing, many still are not research-based. Siden (Siden $\mathrm{H}$, personal communication, March 23, 2007) reported that, of 100 articles related to pediatric palliative care in 55 journals in 2000/2001, 52\% were advisory, descriptive, or review. Though results from Siden's 2005/2006 analysis (Siden $\mathrm{H}$, personal communication, March 23, 2007) showed a decline in the proportion of these types of papers $(41 \%$; 98 out of 238 articles in 91 journals), research results remain limited. Pain and symptom management research papers increased substantially (from 6 to 61 papers), as did the number of qualitative and longitudinal studies (from five to 38 and from to two to 13 respectively) and clinical trials (from one to five). The increase in longitudinal and qualitative research is commendable, given that many of the questions relevant to pediatric palliative care may be more appropriately answered by such methods $(9,10)$.

Researchers from various countries lament the lack of research in pediatric palliative care and have offered suggestions for future research studies. For example, in the U.K., Hunt et al. (11) noted the lack of research into symptomatic pathophysiology, trajectory of disease progression, psychosocial considerations, family experiences, and access to health care resources. In the U.S., Hutton (12) identified six important areas for research: pain and symptom management, prognostication across diagnosis and age groups, designing effective health care systems, health care costs and reimbursement strategies, crosscultural issues, and professional training and support.

In Canada, the Canadian Hospice Palliative Care Association outlined 24 "research priorities" and 29 "potential research questions" (2, pp.58-60) for pediatric palliative care, but did not rank the priorities or questions. Areas for research included but were not limited to: family experiences and issues, ethical issues, com- 
munication, grief and bereavement, quality of life, psychosocial and spiritual issues, health services, pain and symptom management, interdisciplinary teams, culture, and development of outcome measures.

In pediatric oncology, efforts have been made in the U.S. to establish research priorities-palliative and end-of-life care issues have been identified among the top priorities. Specifically, a panel of experts identified three areas of importance: factors in end-of-life decision making; relationships between decisions made and care received; and the effect upon a variety of care endpoints of a relational decisionmaking model that includes parent/guardian, child/adolescent, and health care professional (13). Hinds et al. (14) argued that end-of-life research must be seen as a priority for pediatric oncology, because improving symptom control and end-of-life care might reduce patient suffering and assist families with bereavement issues. These researchers identified five priorities that might improve care outcomes: the characteristics of cancer-related deaths, and the profiles of survivorship in both families and health care professionals; the dying trajectories of children and adolescents, and the models of care that best match each trajectory; end-of-life decision making; financial costs of a pediatric cancer-related death and implications for policy; and outcomes of symptom-directed and bereavement interventions. However, though these priorities may be important, it is difficult to apply them to all children in pediatric palliative care because only about $20 \%$ of children in this population have cancer. Many have progressive neuromuscular or neurodegenerative conditions that will eventually cause their death (15-18) and priorities may be different for these children.

Recommendations for further research have been based on both clinical practice and the limited published research. Researchers across countries have identified similar areas, such as communication, symptom management, and health service delivery issues, but no studies were found that explicitly prioritized research topics in pediatric palliative care. One could argue that all areas are important and the lack of current research means that all areas need to be explored. However, a research program is best built upon a solid rationale and longterm plan.

\section{PURPOSE}

Given the broad scope of suggested research areas and the lack of a clear, methodical, con- sensus-building approach in published work, the PEDPALNET members decided to facilitate a formal approach to identify research priorities in pediatric palliative care. The purpose of this paper is to report on the resulting national study, which used a Delphi approach to identify research priorities considered significant and meaningful to researchers and frontline clinicians in pediatric palliative care in Canada.

\section{METHOD}

The Delphi method chosen for this study allows for exploration of ideas and the formation of an informed group judgment. It is based on a structured process for collecting information about a problem from a panel of experts, analyzing that information, and providing feedback results over two or three rounds until consensus is achieved (19). Originally a postal method, the Delphi technique has been adapted to also include online/Web-based approaches. Researchers clarify a problem, identify and recruit appropriate panelists (people who are able to offer credible opinions and can commit to the process), develop questionnaire statements to be rated by the panelists, and conduct sequential anonymous surveys. The process is iterative, with responses refined and defined over time based on feedback from earlier rounds. One advantage of this approach is that experts from different geographical areas can participate. Another is that the type of social interaction behaviour that can impede group discussion and expression of individual opinions is eliminated because there are no faceto-face interactions. Anonymity and feedback are the two cornerstones of this method. Delphis are not intended to produce statistically significant results, rather they represent the synthesis of opinions from a group of experts and, therefore, "the key to a successful Delphi study lies in the selection of participants" (20). A typical panel size ranges from 15 to 35 , with the expectation that $35 \%$ to $75 \%$ of invitees will actually participate (20).

The Delphi method was considered appropriate for identifying research priorities in pediatric palliative care in Canada because it could easily include experts from across the country, and it offered a streamlined process that was efficient and effective. In addition, the anonymity of the method allowed the small community of experts to express themselves freely. Moreover, Delphis have been used successfully in health care to develop priorities in nursing research (e.g., 21) and to develop quality indicators for evidencebased guidelines (e.g., 19,22). 


\section{Panel Recruitment and Sample}

Purposeful sampling was used to ensure that appropriate experts would be invited to participate. Initially, the team of collaborators from the PEDPALNET identified a list of experts in the field. In addition, the investigators contacted the Canadian Network of Palliative Care for Children, which then forwarded an invitation to its members to participate in the study. The final list consisted of 25 pediatric palliative care health professionals from across Canada, many of whom are also involved in clinical research. The five core PEDPALNET members were excluded from the panel. Attempts were made to formulate a geographically diverse panel and to represent the various disciplines with a role in interdisciplinary palliative care.

Parents and children involved in pediatric palliative care as well as professionals from outside Canada were excluded from the recruitment. In the final round, the panel comprised researchers and clinicians made up of five nurses, six physicians, a social worker, a medical anthropologist, a recreation therapist, a play therapist, and an administrator, thus covering a broad selection of the disciplines usually involved in pediatric palliative care.

\section{Procedures}

Two research assistants (RAs: $\mathrm{HB}$ and MFJ) made the initial contact with the 25 health professionals through electronic mail. They sent each person an introductory letter describing the study, along with the Phase One prompts used to help participants identify questions related to a specific area of patient care, or to a new idea or innovative intervention. If no response was received within two weeks, an RA contacted the potential participant by phone to personally invite him/her to participate and to request permission to once again send the Phase One prompts. A personal telephone call was also made in subsequent phases to any participating panelist who did not respond to a later phase. Completion of the initial request served as consent for Phase One and as agreement to participate in further rounds of the Delphi process.

\section{Data Collection and Analyses}

The study extended over a period of 10 months and involved three phases of data collection and analyses.

Phase One. All 25 health professionals on the panel were asked to identify five research priorities they believed were especially relevant for advancing knowledge in pediatric palliative and end-of-life care. Individuals' responses were copied verbatim into a single list, and then the RAs carefully reviewed the questions (research priorities) for overlap and duplicate content. After eliminating redundancy, the RAs used content analysis of the remaining questions to identify categories that would organize the data. A question that did not fit with any other question was placed in the "other" category. The list and categories were examined and affirmed by a team member (SC).

Phase Two. An RA emailed the 74 questions in their 11 categories to respondents from Phase One for review and evaluation. Participants indicated the level of importance of each of the questions from their perspective in practice. Responses were ranked on an ordinal, 5-point Likert scale, ranging from $1=$ not important to $5=$ very important, and panelists indicated their choice electronically by clicking on the appropriate answer from a dropdown menu. They then saved the completed questionnaire and returned it by email.

Due to the small sample size, the RAs used only descriptive statistics to identify the percentage of consensus among panelists who gave a question a rating of 4 (quite important) or 5 (very important). After considerable discussion by the whole investigating team, the cutoff point for consensus was set at a minimum rating of $66 \%$. There are no firm rules regarding universal consensus levels for Delphi studies. Some authors rely on specific percentages ranging from $51 \%$ to $100 \%$, while others look more towards convergence of opinion with less dispersion over time as an indicator of consensus $(23,24)$. Cutoff points for consensus levels are frequently based on the data rather than on a priori decisions about appropriate percentages. We concluded from our data that a two-thirds level of agreement was reasonable for this relatively small panel.

Phase Three. The 14 questions at or above the consensus cutoff of $66 \%$ were compiled into another questionnaire which was sent to participants from Phase Two. For this final phase, panelists were asked to identify five research priorities from the list. Because these questions had already been rated "quite important" or "very important", further ranking by panelists of their top five answers was not deemed necessary. The RAs calculated the number of panelist responses for each question to determine the consensus percentage and, thus, identified the priorities that achieved the highest rates of consensus. Again, the team discussed a suit- 
able cutoff point. Based on the data as well as our expertise, we concluded that any question with at least $50 \%$ consensus should be deemed a priority.

\section{RESULTS}

A total of 16 of 25 people responded to the initial round, for a response rate of $64 \%$, which is considered acceptable for the Delphi technique (20). While the response rate declined slightly over rounds, it remained at a high level with 15/16 participants responding to the second round and $14 / 15$ completing the third round.

\section{Phase One}

Panelists suggested a total of 74 separate research questions which were collapsed into 11 categories, including an "other" category, for ease of reporting (Appendix 1). The two categories with the most questions were pain and symptom management $(n=13)$ and effect on families $(n=10)$. Questions in the "other" category covered a range of topics.

\section{Phase Two}

At least two-thirds of respondents rated 14 research questions out of the initial 74 as "quite important" or "very important" (Table 1). One question-What matters most for patients and families receiving pediatric palliative services?was rated either "quite" or "very important" by all participants, so there was $100 \%$ consensus on this question. Seven other questions achieved high ratings from $80 \%$ of the panelists and four of those were related to bereavement. Three categories from Phase One covered most of the 14 questions identified as important in this round: pain and symptom management $(n=4)$, effect on families $(n=3)$, and bereavement needs $(n=3)$.

\section{Phase Three}

Analysis of the Phase Three responses revealed the highest level of consensus on four research priorities (Table 2). Consensus ranged from 7\% to $86 \%$ with just four questions above the $50 \%$ cutoff point. The question "What matters most for patients and parents receiving pediatric palliative services?" was ranked as one of the top five priorities by 12 of 14 participants $(86 \%$ consensus). The questions "What are the bereavement needs of families in pediatric palliative care?", "What are the best practice standards in pain and symptom management?", and "What are effective strategies to alleviate suffering at the end of life?" were each ranked in the top five by eight of 14 participants (57\% consensus).

\section{DISCUSSION}

This Delphi method facilitated the identification of current and meaningful research priorities according to front line clinicians, researchers, and administrators across Canada. The panel

Table 1 /DELPHI SURVEY PHASE TWO: 14 RESEARCH QUESTIONS RATED 'QUITE IMPORTANT' OR 'VERY IMPORTANT' BY CANADIAN EXPERTS IN PEDIATRIC PALLIATIVE CARE (consensus cutoff $=66 \%$ )

\begin{tabular}{clc}
\hline Q * & \multicolumn{1}{c}{ Research Question } & Consensus \% \\
\hline 26 & What matters most for patients and parents receiving pediatric palliative services? \\
4 & What are the bereavement needs of families in pediatric palliative care? \\
5 & What strategies are effective in caring for the needs of bereaved siblings? & 100 \\
7 & What is the impact of bereavement follow-up programs (and good quality end-of-life care) on parents' & 80 \\
and siblings' long-term ability to cope with a child's death? & 80 \\
11 & What [bereavement] programs or interventions are most helpful? \\
29 & How can we prepare children for their sibling's death? \\
50 & How do we treat irritability/agitation in children at the end of life? \\
55 & Pharmacological studies to understand control of symptoms including pain \\
37 & How best to integrate and improve palliative care services in a children's hospital? & 80 \\
49 & What are the best practice standards in pain and symptom management? \\
56 & What symptoms are most prevalent for children and what are the best treatments for these symptoms? \\
72 & What are effective strategies to alleviate suffering at the end of life? \\
28 & How do siblings cope? What kinds of support are effective for them? & 80 \\
64 & How do we manage withdrawal of artificial nutrition and hydration? & 73 \\
\hline Table 2 /DELPHI sURVEY PHASE THREE: FOUR PRIORITY RESEARCH QUESTIONS. CONSENSUS \% OF CANADIAN \\
EXPERTS IN PEDIATRIC PALLIATIVE CARE \\
\hline O *
\end{tabular}


of respondents was comprised primarily of physicians and nurses, which is consistent with who often provides the majority of care in pediatric palliative care, but the membership also mirrored the range of interdisciplinary groups typically involved in end-of-life care. The results reflect consensus opinion from appropriate experts, so are considered acceptable and pertinent (20).

The general areas of family experiences, pain and symptom management, bereavement, and suffering at the end of life achieved the highest consensus percentages. These areas have all previously been identified by researchers and clinicians in various countries as requiring investigation $(2,11,12)$. Some researchers are currently exploring these areas, although such work remains limited.

\section{Family Experiences}

It is necessary to understand the experiences of families if clinicians are to provide the most appropriate care. This area has been identified implicitly by the AAP (8) and IOM (9) in recommendations for research that will lead to more effective care. Other authors and organizations explicitly noted the lack of research on family experiences (e.g., 2,11).

The number of reported studies about family experiences has been increasing. A search of published literature between 1997 and 2007 revealed some 53 articles reporting on 41 studies. To give just two recent examples, Steele and Davies (25) reported that the impact on parents of caring for a child with a neurodegenerative illness was pervasive and multidimensional. Parents face many emotional, physical, financial, and spiritual effects on their lives. They often need help to alleviate the effect of their experience, but help is not always available in a useful manner. In another study, Hays et al. (26) found that patient-provider communication was central to families. They noted that pediatric palliative care services that focus on effective communication, decision support, and co-case management with insurers can improve aspects of quality of life and family satisfaction. While recruitment with this population may be challenging (27), it is important the perspective of families be more fully understood.

Given the importance of understanding family experiences, it must also be acknowledged that the particular question generated in this Delphi, "What matters most for patients and parents receiving pediatric palliative services?", is complex and potentially problematic. What matters for patients of pediatric palliative care may be different from parents of those children. It is important to ensure that all voices are heard and one person's perspective, for example a parent's view, is not accepted as always reflecting the experience of individual family members. Rather, an attempt must be made to understand each person's perspective.

\section{Pain and Symptom Management}

Virtually every call for research in pediatric palliative care has noted that improved knowledge about pain and symptom management/ interventions is critical (e.g., 2,8,9,11,12,14). But pain management has also been noted to be challenging in the context of pediatric palliative care (28).

There is a trend towards more published research in the pain and symptom management area than any other area. Both nonpharmacological (e.g., distraction, imagery, and relaxation) and pharmacological (e.g., opiods) methods have been reported as useful in ensuring adequate symptom control in children facing end of life (28). Hooke et al. (29) showed through a chart review that propofol is a useful and tolerable adjuvant agent for pain management in pediatric oncology patients at the end of life, especially if pain is unresponsive to continuous infusion opioids or if rapidly escalating doses of opioids are required.

Goldman et al. (30) documented the frequency of multiple symptoms in children/young people with cancer, some of which often go unrecognized, such as anorexia, weight loss, and weakness. Pain and neurologic symptoms, including headache, were also reported. They noted that with access to skilled symptom control, pain can be effectively treated in most children/young people, but some other symptoms may remain intractable. This study highlighted the need for further research to establish the effectiveness of therapeutic interventions for control of symptoms and their effect on the quality of life for children/young people dying from cancer.

In a review article, Poltorak and Benore (31) discussed how psychological factors can exacerbate physical symptoms or influence the perception of symptoms in children with advanced disease. They encouraged the continued investigation of cognitive-behavioural interventions (CBIs) in pediatric palliation because CBIs have produced positive outcomes for the management of symptoms across various disease populations. They noted that children tend to be receptive to these noninvasive interventions, which can decrease fear and anxiety, and improve overall coping. 
Symptoms of post-traumatic stress disorder (PTSD) have been reported in response to a variety of life-threatening medical illnesses and injuries in adults and children. PTSD researchers have found that parents of medically ill children were at least as symptomatic as, if not more than their children (32). This finding supports the importance of a family-focused approach in pediatric palliative care, especially as emerging evidence suggests that PTSD in life-threatening pediatric illness is treatable when it occurs, and may even be prevented, thus affecting a child and family's quality of life.

\section{Bereavement}

The need for research into bereavement issues has been highlighted by a number of authors and organizations (e.g., 2,8,9,14), and there is some current reported research around bereavement.

In one study, researchers evaluated a program of bereavement follow up through the pediatric palliative care team at Capital Health's Stollery Children's Hospital in Edmonton, Alberta, Canada (33). Parents reported that written information about loss and grief was useful to them and having a resource person available to answer questions was supportive. They also felt that the program was an important extension of the care given by the Stollery staff throughout their child's illness and death.

deCinque et al. (34) recently explored the experiences and needs of parents in Western Australia who had received hospital-based bereavement support following the death of their child from cancer. Parents identified the need for more supportive contact from hospital staff during the palliative phase and following the child's death; early provision of information on how, practically and emotionally, to prepare for the death of their child; contact with other bereaved parents; and formal grief support for siblings. Suggested areas for future research included exploration of parents' wishes to become involved in activities to help others, bereavement support for siblings, the level of contact with the hospital unit that families desire, and parental behaviours associated with accessing both hospital and community-based bereavement supports.

\section{Alleviating Suffering at the End of Life}

The many aspects of human suffering include physical, psychological, social, and spiritual (35). In pediatric palliative care, not only may the ill children suffer $(36)$, but their families $(37,38)$ and the health care professionals looking after them (39) may also suffer. The IOM (9) stated that too often there is a lack of care that meets the needs of children and families. The same might be said about meeting the needs of the health care professionals involved with their care.

Human suffering should not be seen as a medical problem, though there is obviously a need to alleviate physical and psychological issues where present. Rather, suffering must be examined in light of human nature and our need for relationships (40). The relationships that are formed between children with life-threatening illnesses, their families, and their caregivers will affect the quality of life of all concerned. It is imperative, therefore, that research be conducted to examine the multiple dimensions of all who suffer in pediatric palliative care and to explore these relationships in order to better understand ways to minimize suffering.

Overall, the priority areas for research in this Delphi study concur with previously identified research needs, although priorities had not been explicitly or methodically identified elsewhere. They also complement the work that some researchers are currently undertaking.

\section{Potential Barrier to Research in Pediatric Pal- liative Care}

Clearly, there is a need for systematic development of research evidence in pediatric palliative care. However, as indicated earlier, a more recent review of published literature about pediatric palliative care continues to indicate several review articles, but limited reports of research (Siden $\mathrm{H}$, personal communication, March 23, 2007). One challenge to increasing the amount of research may be that children and families in pediatric palliative care are viewed by clinicians, ethics board reviewers, and researchers as vulnerable populations (37). There is often reluctance to include vulnerable people in research, yet one could argue that only those undergoing an experience can provide subjective evidence about the experience. Obviously, research with vulnerable populations must be undertaken with care and sensitivity, but willing participants should not be excluded because of professional perceptions of possible harm.

Recent studies have shown that families may not only want to take part in research, but they may actually benefit in some way (37). For example, bereaved parents in some studies (e.g., 41-46) have reported that their participation in research was emotionally difficult at times, but overall it was a positive experience. Steele (47) found that participating in research was one way that parents created meaning around their child's illness and its consequences. Research- 
ers must gather more evidence of the positive outcomes of involving families in pediatric palliative care research if the needed work is to be done.

\section{Limitations}

Several limitations require cautious interpretation of the findings of this Delphi study. First, the sample size is relatively small, though adequate for the consensus building strategy of a Delphi process. However, the sample size in round one was indicative of the size of the Canadian community of pediatric palliative research and practice, and realistically could not have been increased. Second, the study was conducted solely in Canada and so may lack generalization to other countries, though it is expected that other countries could learn from this work. The decision to focus on a Canadian sample was based in PEDPALNET's desire to establish priorities within Canada, in part because the funding came from a national source. Future research, however, could expand the sample size and breadth by including experts from anywhere in the world, as the study could be replicated to include any participant who has access to the Internet.

Third, the initial research questions identified by the panel included a wide array of issues with varying degrees of depth. However, the topics where participants eventually reached a consensus were broad and quite unspecific, which was somewhat problematic. For example, the complexity of the top question that involves both patient and family raises the possibility of losing the voices of children and perhaps leaving intra-familial tensions unrecognized. So, further work needs to be done to unpack the similarities and differences between patient and family needs to ensure all voices are heard equally. Future exploration of research priorities, such as a global Delphi study, might benefit from ensuring topics are more specific to prevent possible conflation of issues. Such an approach should then simplify development of specific research questions to address the priority areas.

Fourth, and most importantly, the sample excludes the voices of patients and families. The decision not to include families was made in order to concentrate on research rather than clinical priorities and to mitigate the possibility that parents might have difficulty identifying needs beyond those of their own child. The identification of research priorities could be further explored (and hopefully validated) through a consultation process with families. Soanes et al. $(48,49)$ provide an example of a Delphi process on research priorities for nurses that was further validated with physicians and parents. Future research by PEDPALNET needs to undertake the process of validating these priorities with those who are most affected by life-threatening illness: families.

\section{Future Research}

The identification of research priorities in pediatric palliative care emphasizes the critical need for more research in this field. The members of PEDPALNET are working to address some of these important lines of inquiry, frequently in collaboration with other researchers and clinicians across the country. For instance, a multisite longitudinal study is in development to address physical and psychological changes in pediatric patients diagnosed with life-threatening illnesses and their families, including siblings. This research involves numerous pediatric palliative and metabolic diseases specialists with whom we have not previously collaborated, and will provide insight into best practice standards in pain and symptom management. Research is also underway concerning the experience of bereavement in parents whose child has died of a life-limiting illness. Additionally, a study of the experiences of Chinese-Canadian families with pediatric palliative care is in progress. These projects are contributing to the preparation of the next generation of scholars for pediatric palliative research via PEDPALNET's program of education and mentorship for students. While these various projects use a range of methodologies, we consider qualitative and mixed methods to be of greatest benefit for answering questions from both the patient and family perspective.

\section{CONCLUSION}

In this Canadian Delphi study, the areas of family experiences, pain and symptom management, bereavement, and alleviating suffering at the end of life were identified as the most important priorities for research. Given that the results from this study concur with previous suggestions from researchers in several countries about required research in pediatric palliative care, it seems these areas warrant immediate attention. While some research has been conducted in these areas, there is a clear need for increased and targeted research efforts. The PEDPALNET is using the identified priorities to provide guidance and direction for research efforts in Canada. These priorities may also prove useful internationally, as all clinicians and researchers work toward providing optimal care to patients and families in pediatric palliative care. 
Date received, October 24, 2007; date accepted, April 9,2008

\section{ACKNOWLEDGEMENTS}

This work was supported by Canadian Institutes of Health Research (CIHR) grant PET-69769. Thanks also to Ms. Carly Fleming and Ms. Lisa Jacques for administrative assistance, and to Ms. Kim Widger for her critical review of a draft of this manuscript.

\section{REFERENCES}

1. World Health Organization. WHO Definition of

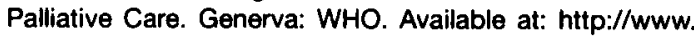
who.int/cancer/palliative/definition/en/. Accessed July 6 , 2006.

2. Canadian Hospice Palliative Care Association, Canadian Network of Palliative Care for Children. Pediatric Hospice Palliative Care: Guiding principles and norms of practice. Ottawa: CHPCA, March 2006.

3. Mack JW, Wolfe J. Early integration of pediatric palliative care: For some children, palliative care starts at diagnosis. Curr Opin Pediatr 2006; 18(1): 10-4 .

4. Association for Children with Life-Threatening or Terminal Conditions and their Families (ACT), Royal College of Paediatrics and Child Health. A Guide to the development of children's palliative care services. London: RCPCH, September 2003.

5. Statistics Canada, Health Statistics Division. Mortality, Summary List of Causes. 2003; 84F0209XIE. Ottawa: Statistics Canada, 2003.

6. Lenton $S$, Stallard $P$, Lewis $M$, Mastroyannopoulou $K$. Prevalence and morbidity associated with non-malignant, life-threatening conditions in childhood. Child Care Health Dev 2001; 27(5): 389-398.

7. Cooley C, Adeodu S, Aldred H, Beesley S, Leung A, Thacker L. Paediatric palliative care: a lack of researchbased evidence. Int J Palliat Nurs 2000; 6(7): 346-351.

8. American Academy of Pediatrics, Committee on Bioethics and Committee on Hospital Care. Palliative care for children. Pediatrics 2000; 106(2 Pt 1): 351-357.

9. Committee on Palliative and End-of-Life Care for Children and Their Families. Board on Health Sciences Policy, eds. When Children Die: Improving palliative and end of life care for children and their families. Washington, D.C.: The National Academies Press, 2003.

10. Pritchard $M$, Davies $B$. End of life in pediatric oncology: How clinical practice leads to research. J Pediatr Oncol Nurs 2002; 19(6): 191-197.

11. Hunt $A$, Hain $R$, Jassal $S$, Thompson A. Pediatric palliative care: Where and what is published? Arch Dis Child 2003; 88(suppl 1): A61-A63.

12. Hutton N. Pediatric palliative care: The time has come. Arch Pediatr Adolesc Med 2002; 156(1): 9-10.

13. Hare ML. Comparing research priorities for pediatric oncology from two panels of experts. Semin Oncol Nurs 2005; 21(2): 145-150.

14. Hinds PS, Pritchard $M$, Harper J. End-of-life research as a priority for pediatric oncology. J Pediatr Oncol Nurs 2004; 21(3): 175-179.

15. Ashby MA, Kosky RJ, Laver HT, Sims EB. An enquiry into death and dying at the Adelaide Children's Hospital: A useful model? Med J Aust. 1991; 154(3): 165-170.

16. Davies B. Howell D. Special services for children. In: Doyle D, Hanks G, MacDonald N (eds). Oxford Textbook of Palliative Medicine. $2^{\text {nd }}$ edition. Oxford, UK: Oxford University Press; 1998, pp. 1077-1084.

17. Goldman A. Home care of the dying child. J Palliat Care 1996; 12(3): 16-19.

18. Widger K, Davies D, Drouin DJ, Beaune L, Daoust L, Farran RP, et al. Pediatric patients receiving palliative care in Canada: results of a multicenter review. Arch Pediatr Adolesc Med 2007; 161(6): 597-602.

19. Campbell SM, Braspenning $J$, Hutchinson $A$, Marshall MN. Research methods used in developing and applying quality indicators in primary care. Brit Med $\mathrm{J}$ 2003; 326(7393): 816-819.

20. Gordon TJ. The Delphi Method. 1994. Available at: http://www.futurovenezuela.org/_curso/5-delphi.pdf Accessed March 26, 2007.

21. Annells $M$, Deroche $M$, Koch $T$, Lewin G, Lucke J. A Delphi study of district nursing research priorities in Australia. Appl Nurs Res 2005; 18(1): 36-43.

22. Hermens RP, Ouwens MM, Vonk-Okhuijsen SY, van der Wel $Y$, Tjan-Heijnen VC, van den Broek $L O$, et al Development of quality indicators for diagnosis and treatment of patients with non-small cell lung cancer: a first step toward implementing a multidisciplinary, evidencebased guideline. Lung Cancer 2006; 54(1): 117-124.

23. Hasson F, Keeney $S$, McKenna $H$. Research guidelines for the Delphi survey technique. J Adv Nurs 2000; 32(4): 1008-1015.

24. Powell $C$. The Delphi technique: myths and realities. J Adv Nurs 2003; 41(4): 376-382.

25. Steele R, Davies B. Impact on parents when a child has a progressive, life-threatening illness. Int $\mathrm{J}$ Palliat Nurs 2006; 12(12): 576-585.

26. Hays RM, Valentine J, Haynes G, Geyer JR, Villareale N, McKinstry $B$, et al. The Seattle Pediatric Palliative Care Project: effects on family satisfaction and healthrelated quality of life. J Palliat Mod 2006; 9(3): 716-728.

27. Tomlinson D, Bartels, U, Hendershot E, Constantin $J$, Wrathall G, Sung, L. Challenges to participation in paediatric palliative care research: a review of the literature. Palliat Med 2007; 21(1): 435-440.

28. Gregoire MC, Frager G. Ensuring pain relief for children at the end of life. Pain Res Manag 2006; 11(3): 163-171.

29. Hooke MC, Grund E, Quammen H, Miller B, McCormick P, Bostrom B. Propofol use in pediatric patients with severe cancer pain at the end of life. J Pediatr Oncol Nurs 2007; 24(1): 29-34.

30. Goldman $A$, Hewitt $M$, Collins GS, Childs $M$, Hain R. Symptoms in children/young people with progressive malignant disease: United Kingdom Children's Cancer Study Group/Paediatric Oncology Nurses Forum survey. Pediatrics 2006; 117(6): e1179-e1186.

31. Poltorak DY, Benore E. Cognitive-behavioral interventions for physical symptom management in pediatric palliative medicine. Child Adolesc Psychiatr Clin N Am 2006; 15(3): 683-691.

32. Stuber ML, Shemesh E. Post-traumatic stress response to life-threatening illnesses in children and their parents. Child Adolesc Psychiatr Clin N Am 2006; 15(3): 597-609.

33. deJong-Berg MA, Kane L. Bereavement care for families. Part 2: Evaluation of a paediatric follow-up programme. Int J Palliat Nurs 2006; 12(10): 484-494.

34. deCinque N, Monterosso L, Dadd G, Sidhu R, Macpherson R, Aoun S. Bereavement support for families following the death of a child from cancer: experience of bereaved parents. J Psychosoc Oncol 2006; 24(2): 65-83.

35. Hinds PS, Schum L, Baker JN, Wolfe J. Key factors affecting dying children and their families. J Palliat Med 2005; 8 (suppl 1): S70-S78.

36. Wolfe J, Grier HE, Klar N, Levin SB, Ellenbogen JM, Salem-Schatz $S$, et al. Symptoms and suffering at the end of life in children with cancer. N Engl J Med 2000; 342(5): 326-333.

37. Hinds PS, Burghen EA, Pritchard $M$. Conducting end-of-life studies in pediatric oncology. West $J$ Nurs Res 2007; 29(4): 448-465.

38. Houlahan KE, Branowicki PA, Mack JW, Dinning C, McCabe M. Can end of life care for the pediatric patient suffering with escalating and intractable symptoms be improved? J Pediatr Oncol Nurs 2006; 23(1): 45-51. 
39. Rushton $\mathrm{CH}$, Reder $\mathrm{E}$, Hall $\mathrm{B}$, Comello $\mathrm{K}$, Sellers $D E$, Hutton $N$. Interdisciplinary interventions to improve pediatric palliative care and reduce health care professional suffering. J Palliat Med 2006; 9(4): 922-933.

40. Kane JR, Hellsten MB, Coldsmith A. Human suffering: the need for relationship-based research in pediatric endof-life care. J Pediatr Oncol Nurs 2004; 21(3): 180-185.

41. Contro N, Larson J, Scofield S, Sourkes B, Cohen $\mathrm{H}$. Family perspectives on the quality of pediatric palliative care [comment]. Arch Pediatr Adolesc Med 2002; 156(1): 14-19.

42. Hynson JL, Aroni R, Bauld C, Sawyer SM. Research with bereaved parents: A question of how not why. Palliat Med 2006; 20(8): 805-811.

43. Kreicbergs $U$, Valdimarsdottir U, Steineck G, Henter JI. A population-based nationwide study of parents' perceptions of a questionnaire on their child's death due to cancer. Lancet 2004; 364(9436): 787-789.

44. Meyer EC, Burns JP, Griffith JL, Truog RD. Parental perspectives on end-of-life care in the pediatric intensive care unit. Crit Care Med 2002; 30(1): 226-231.
45. Tomlinson D, Capra M, Gammon J, Volpe J, Barrera $M$, Hinds PS, et al. Parental decision making in pediatric cancer end-of-life care: Using focus group methodology as a prephase to seek participant design input. Eur $\mathrm{J}$ Oncol Nurs 2006; 10(3): 198-206.

46. Woodgate RL. Living in a world without closure: reality for parents who have experienced the death of a child. J Palliat Care 2006; 22(2): 75-82.

47. Steele R. Strategies used by families to navigate uncharted territory when a child is dying. J Palliat Care 2005; 21(2): 103-110.

48. Soanes L, Gibson F, Bayliss J, Hannan J. Establishing nursing research priorities on a paediatric haematology, oncology, immunology and infectious diseases unit: a Delphi Survey. Eur J Oncol Nurs 2000; 4(2): 108-117.

49. Soanes L, Gibson F, Hannan J, Bayliss J. Establishing nursing research priorities on a paediatric haematology, oncology, immunology and infectious diseases unit: involving doctors and parents. Eur $\mathrm{J}$ Oncol Nurs 2003; 7(2): 110-119.

\section{Appendix 1 / DELPHI SURVEY PHASE ONE RESULTS}

Questionnaire by category for rating initial 74 questions generated by panel of Canadian experts in pediatric palliative care

Category One: Professional Caregivers

1. What is the experience of professional caregivers in pediatric palliative care?

2. What factors influence job satisfaction and long-term commitment?

3. What is the most effective means of support for staff?

\section{Category Two: Bereavement Needs}

4. What are the bereavement needs of families in pediatric palliative care?

5. What strategies are effective in caring for the needs of bereaved siblings?

6. Do cultural norms help or hinder the grieving process?

7. What is the impact of bereavement follow-up programs (and good quality end-of-life care) on parents' and siblings' long term ability to cope with a child's death?

8. What is the prevalence of suicidal ideation in bereaved parents when a child dies from a protracted illness, rather than when a child dies a sudden violent death (injury, homicide, suicide)?

9. How long should bereavement services be offered to a family?

10. Does making memories with a child (special planned activities/events) prior to their death facilitate grief healing?

Category Three: Bereavement Programs

11. What programs or interventions are most helpful?

12. How do we evaluate bereavement support for the family and the care team?

13. What purpose do practitioners/clinicians believe bereavement follow up is serving?

14. What is the most appropriate bereavement follow up for families and how can this be identified?

Category Four: Informed Consent and Decision Making

15. What is informed consent in pediatric palliative care?

16. What is the professional's responsibility for discussion with children/youth?

17. What level of involvement in end-of-life decision making is desired by children and adolescents?

18. How do we obtain consensus on certain areas of treatment such as: treatment of respiratory problems; treatment of asthenia; use of unusual treatments such as anti-arrhythmics for the treatment of pain?

19. What tools can be used to discuss and document advance care planning with families of children with life-limiting illness? How can these be implemented at an institutional/systems level to allow seamless care?

20. How do we discuss advanced directives in pediatric palliative care?

\section{Category Five: Effect on Families}

21. What is the effect on families who have a child with a progressive illness and complex care needs?

22. Does the complexity of care or the length of care have an effect on functioning and outcomes for parents, siblings, and extended family?

23. What factors influence the emotional well-being of relationships in couples experiencing services for a child towards the end of life?

24. What is the experience of families who have a nonverbal child who is dying? What intervention/support is helpful for their experience?

25. What is the experience of culturally diverse families who have a child receiving palliative care in a Canadian health care climate?

26. What matters most for patients and parents receiving pediatric palliative services?

27. What are family's perceptions of being present during a child's attempted resuscitation?

28. How do siblings cope? What kinds of support are effective for them?

29. How can we prepare children for their sibling's death?

30. What is the impact on siblings coping with pediatric palliative care? 


\section{Category Six: Evaluation}

31. How do patients, parents, and health professionals evaluate the quality of pediatric end-of-life/palliative care?

32. Evaluation of hospice, home care, and hospital programs from a cost vs. burden perspective for the family and care team.

33. What is the meaning and experience of family-centred care from a family's perspective?

34. What model of a palliative care team is the most effective for patient care?

35. How can we measure the impact of existing palliative care teams on patients and their families?

36. What are the perceived gaps in pediatric palliative care services according to health care staff presently caring for children with life-limiting illness?

\section{Category Seven: Integration and Improvement of Services}

37. How best to integrate and improve palliative care services into a children's hospital?

38. What are effective strategies for integrating into particular settings (emergency room, NICU, PICU)?

39. What are the attitudes towards palliative care in critical care settings?

40. What do we understand about the transition from active treatment to palliative care?

41. How is transitioning accomplished in the various environments in pediatric palliative care (e.g., ICU, chronic disease groups) and could this be improved upon?

42. How can we better understand how to overcome barriers to giving children and families access to pediatric palliative care services?

\section{Category Eight: Education and Training}

43. What formal curriculum content exists in universities across the country for pediatric palliative care training in medical and nursing disciplines?

44. How prepared do specific groups of physicians (general pediatricians, pediatric hematologist /oncologist, pediatric intensive care specialists, family physicians, palliative care consultant physicians, senior residents training in pediatrics) feel to provide high quality pediatric and end-of-life care for children?

45. What are the best methods of teaching a specialization to physicians?

46. What is an effective strategy to help pediatricians better understand and accept palliative care?

47. How do we learn effective communication with children and families at the end of life?

48. What are the tools professional health providers need to be able to communicate effectively with families in pediatric palliative care?

\section{Category Nine: Pain and Symptom Management}

49. What are the best practice standards in pain and symptom management?

50. How do we treat irritability/agitation in children at the end of life?

51. What is the impact/effectiveness of a pediatric palliative care consultation service on symptom management?

52. Is ketamine a useful adjuvant treatment for cancer pain poorly controlled by opioids in pediatric patients?

53. Can we develop consensus expert opinion on protocols for methadone use in children?

54. Is methadone a superior analgesic agent for pediatric cancer pain when studied as it is used in practice?

55. Pharmacological studies to understand control of symptoms including pain.

56. What symptoms are most prevalent for children and what are the best treatments for these symptoms?

57. What is the impact of complementary therapies on symptoms and quality of life for children?

58. What is the incidence/prevalence of parents seeking unproven or disproven alternative therapies when their child is receiving end-of-life care?

59. How do we understand self-evaluation of symptoms by children?

60. What are families' experiences with end-of-life care? Are the distressing symptoms well managed?

61. Validation of tools for assessment in pediatric palliative care symptom management.

\section{Category Ten: Nutrition and Feeding Issues}

62. What are the reasonable strategies for managing nutritional failure in pediatric palliative care?

63. How do we manage feeding issues in patients with neurological dysfunction and feeding intolerance?

64. How do we manage withdrawal of artificial nutrition and hydration?

65. What are the medical, ethical, and legal standards addressing withdrawal of feeds in neurologically impaired infants, children, and adolescents?

\section{Category Eleven: Other}

66. Withdrawal of medical interventions-Have medical advances gone too far? Are we saving children who shouldn't be saved?

67. What national policies correlate best with the advancement of practice in pediatric palliative care?

68. What are the critical factors of success in developing a functional free-standing hospice for children?

69. How can a national advocacy strategy work in a fragmented area that lacks coordination?

70. What is the best way of doing research in pediatric palliative care? Are there specific norms of practice for research?

71. Does the concurrent involvement of a pediatric pain care service (or pain and symptom control service) with the care team in phase I clinical trials in chemotherapy for cancer influence certain health care utilization indicators: a) number of days; b) emergency room visits; and c) location of death?

72. What are effective strategies to alleviate suffering at the end of life?

73. What is the current state of palliative care involvement with families prenatally when life-limiting illness is expected? What effect has palliative care involvement made on these families and the health care team?

74. Children with disabilities and integration: creating an empathic generation or a generation of ill educated children because of classroom disruption and the attention teacher has to spend with the child? 